\title{
The comparison of transurethral versus suprapubic catheter after robot-assisted radical prostatectomy: a systematic review and meta-analysis
}

\author{
Ze'an $\mathrm{Li}^{1,2 \#}$, Kaiwen $\mathrm{Li}^{1,2 \#}$, Wanhua $\mathrm{Wu}^{1,2 \#}$, Qiong Wang ${ }^{1,2}$, Xiaoming $\mathrm{Ma}^{1,2}$, Chunhao Lin ${ }^{1,2}$, \\ Shengmeng Peng ${ }^{1,2}$, Yiming Lai ${ }^{1,2}$, Fen Wang ${ }^{3}$, Hai Huang ${ }^{1,2,3}$ \\ ${ }^{1}$ Department of Urology, Sun Yat-sen Memorial Hospital, Sun Yat-sen University, Guangzhou 510120, China; ${ }^{2}$ Guangdong Provincial Key \\ Laboratory of Malignant Tumor Epigenetics and Gene Regulation, Sun Yat-sen Memorial Hospital, Sun Yat-sen University, Guangzhou 510120, \\ China; ${ }^{3}$ Center for Cancer and Stem Cell Biology, Institute of Biosciences and Technology, Texas A\&M Health Science Center, Houston, TX \\ 77030, USA \\ Contributions: (I) Conception and design: Z Li, K Li; (II) Administrative support: H Huang, F Wang, Y Lai; (III) Provision of study material or \\ patients: Z Li, Q Wang, S Peng; (IV) Collection and assembly of data: Z Li, W Wu, Y Lai; (V) Data analysis and interpretation: Z Li, X Ma, C Lin; (VI) \\ Manuscript writing: All authors; (VII) Final approval of manuscript: All authors. \\ \#These authors contributed equally to this work. \\ Correspondence to: Hai Huang. Department of Urology, Sun Yat-sen Memorial Hospital, Sun Yat-sen University, Guangzhou 510120, China. \\ Email: huanghai257@126.com; Fen Wang. Center for Cancer and Stem Cell Biology, Institute of Biosciences and Technology, Texas A\&M Health \\ Science Center, Houston, TX 77030, USA. Email: fwang@ibt.tamhsc.edu.
}

\begin{abstract}
Background: The transurethral catheter (TUC) or supra-pubic catheter is commonly used after robotassisted radical prostatectomy (RARP). However, the best way of urine drainage after the operation is still controversial.

Methods: A comprehensive search of PubMed, Cochrane, Web of Science databases and the reference lists of relevant articles was performed up to July 2019. This systematic review and meta-analysis was performed based on all randomized controlled trials (RCTs) and retrospective studies assessing the two techniques.

Results: In total, nine studies (1,121 patients) were eligible, including three RCTs, one prospective and five retrospective studies. After RARP, postoperative pain was less in suprapubic catheter (SPC) group than TC group, both within 3 days [mean difference (MD): $-0.70 ; 95 \%$ confidence interval (CI): -1.37 to $-0.02 ; \mathrm{P}=0.04]$ and 5 days after operation (MD: $-0.96 ; 95 \% \mathrm{CI}:-1.39$ to $-0.52 ; \mathrm{P}<0.00001)$. There was no significant difference between SPC and TUC groups, in operation time (MD: 2.58; 95\% CI: -5.82 to 10.97; $\mathrm{P}=0.55)$ and at rates of both catheterization-associated complication [odds ratio (OR): $1.05 ; 95 \%$ CI: 0.67 to 1.64; $\mathrm{P}=0.83$ ] and long-term urinary incontinence (OR: 0.69; 95\% CI: 0.42 to $1.12 ; \mathrm{P}=0.13$ ).
\end{abstract}

Conclusions: Patients in SPC group suffer from less postoperative pain compared with the TUC group. SPC can be a better alternate of TUC.

Keywords: Catheter; prostatectomy; robot-assisted; suprapubic; meta-analysis

Submitted Apr 10, 2019. Accepted for publication Aug 02, 2019.

doi: $10.21037 /$ tau.2019.08.25

View this article at: http://dx.doi.org/10.21037/tau.2019.08.25

\section{Introduction}

Prostate cancer is the second most commonly diagnosed malignancy and the fifth leading cause of cancer death in men worldwide $(1,2)$. Radical prostatectomy is a therapeutic approach to patients with low- and intermediate-risk prostate cancer.

Robot-assisted radical prostatectomy (RARP) has the advantages in terms of perioperative outcomes, postoperative complications and long-term continence $(3,4)$. After the 
operation, the transurethral catheter (TUC) is mostly used, which remains a major source of pain and discomfort (5).

To minimize postoperative pain, suprapubic catheter (SPC) has been used in cardiothoracic (6) and abdominal operation (7), which had indicated that SPC had less postoperative pain and discomfort compared to TUC. Furthermore, SPC is associated with a low incidence of urethral injury, urinary tract infection and other complications (7-10). SPC has been accepted by urologists since a custom-made SPC used after RARP by Tewari et al. in 2008 (11).

However, whether SPC is better than TUC after RARP remains unclear. The present study is to perform a systematic review and meta-analysis to evaluate the benefits of SPC compared with TUC after RARP.

\section{Methods}

A prospective protocol of literature-search strategies, inclusion and exclusion criteria, outcome measurements, quality assessment and methods of data analysis was prepared a priori according to the Preferred Reporting Items for Systematic Reviews and Meta-analysis and Meta-analysis of Observational Studies in Epidemiology recommendations for study reporting $(12,13)$.

\section{Literature search strategy}

A literature search was performed in PubMed, Cochrane, Web of Science databases on July 25, 2019, and was restricted to the English language. The following MeSH terms and their combinations were searched in (Title/ Abstract): catheter/catheterization, prostatectomy. The details of the search strategy were given in Appendix 1. The Related Articles function was also used to broaden the search, and the computer search was supplemented with manual searches of the reference lists of all related articles. When multiple reports describing the same population were published, the most recent or complete report was used.

\section{Inclusion and exclusion criteria}

All randomized controlled trials (RCTs) and observational comparative studies comparing TUC and SPC after RARP and had at least one of the quantitative outcomes were included. Single-arm series, editorials, comments, letters to the editor, review articles, case reports and experimental animal studies were excluded (Table 1).

\section{Data extraction and outcomes of interest}

Data from the included studies were extracted and summarized independently by two of the authors $(\mathrm{Li} \mathrm{Z}$ and $\mathrm{Li} \mathrm{K}$ ). Any disagreement was resolved by the adjudicating senior authors (Huang $\mathrm{H}$ and Wang F).

The primary outcome was postoperative pain. It was divided into early postoperative pain [within postoperative day $3(\leq$ POD3)] and later postoperative pain $(\geq$ POD5). Postoperative pain was evaluated using a visual analog scale (VAS) or Numeric Rating Scale (NRS).

The secondary outcomes were long-term (>30 days) urinary incontinence ( $>1$ pad per day), operation time and complications related to catheterization including urinary retention, catheter malfunction, bladder spasm, bladder neck contracture, urinary tract infection, and hematuria (Table 1, Table S1).

\section{Quality assessment}

Studies were rated for the level of evidence provided according to criteria by the Centre for Evidence-Based Medicine in Oxford, UK (14) .

The methodological quality of RCTs was assessed by the Cochrane risk of bias tool (15). The methodological quality of retrospective studies was assessed by the modified Newcastle-Ottawa scale $(16,17)$. A score of $0-9$ was allocated to each study except RCTs.

\section{Statistical analysis}

The meta-analyses were performed using Review Manager 5 (Cochrane Collaboration, Oxford, UK). The mean difference (MD) and odds ratio (OR) were used to compare continuous and dichotomous variables, respectively. All results were reported with $95 \%$ CI. For studies that presented continuous data as median, interquartile range or range values, the mean and standard deviations were calculated or estimated using the technique described by Hozo et al. or Wan et al. (18-20). The mean value of the data only reported in the studies would be removed.

Statistical heterogeneity between studies was assessed using the chi-square test with significance set at $\mathrm{P}<0.10$, and heterogeneity was quantified using the $\mathrm{I}^{2}$ statistic. The random-effects model was used if there was heterogeneity between studies; otherwise, the fixed-effects model was used (15).

Subgroup analyses were performed. The included 
Table 1 study criteria for inclusion and exclusion in the review

\begin{tabular}{|c|c|c|}
\hline Variables & Inclusion criteria & Exclusion criteria \\
\hline \multirow[t]{2}{*}{$\begin{array}{l}\text { Types of } \\
\text { intervention }\end{array}$} & $\begin{array}{l}\text { All studies evaluating suprapubic catheter (SPC) after RARP, defined as: (I) catheter was } \\
\text { passed through the inferior incision above the symphysis pubis or through the wound } \\
\text { for the robotic system's arms; (II) the patients requiring SPC without or with additional } \\
\text { transurethral catheter after RARP for one day or several days }\end{array}$ & \\
\hline & $\begin{array}{l}\text { Compared with transurethral catheter (TUC) after RARP, defined as: the patients requiring } \\
\text { catheter through the penis into bladder }\end{array}$ & \\
\hline \multirow{8}{*}{$\begin{array}{l}\text { Types of } \\
\text { outcome } \\
\text { measures }\end{array}$} & All studies included one or more of the following & \\
\hline & Primary outcomes [measured by visual analog scale (VAS) or other scale] & \\
\hline & Secondary outcomes & \\
\hline & Urinary incontinence (>1 pad per day) & \\
\hline & Urinary tract infection & \\
\hline & Hemateuresis & \\
\hline & $\begin{array}{l}\text { Complication related to catheter (i.e., clot retention, urinary retention, catheter malfunction, } \\
\text { bladder spasm, bladder neck contracture, urinary tract infection, hematuria, skin irritation) }\end{array}$ & \\
\hline & Duration time of operation & \\
\hline $\begin{array}{l}\text { Types of } \\
\text { study }\end{array}$ & $\begin{array}{l}\text { All comparative studies (i.e., randomized clinical trial) and nonrandomized comparative } \\
\text { studies (i.e., Prospective collective data, retrospective studies) }\end{array}$ & $\begin{array}{l}\text { Single-arm series, case } \\
\text { reports, editorial or } \\
\text { commentaries }\end{array}$ \\
\hline
\end{tabular}

studies were grouped into RCT group and Not RCT group which contain retrospective studies and prospective nonrandomized trials. Publication bias was assessed by funnel plot.

\section{Results}

\section{Results of the search}

Nine studies (11,21-28) including 1,121 patients (585 patients for SPC and 536 patients for TUC) fulfilled the predefined inclusion criteria and were included in the final analysis (Figure 1).

\section{Risk of bias and methodological quality of included studies}

Three RCTs of 9 studies were assessed by Cochrane risk of bias tool and the other six retrospective studies were assessed by the modified Newcastle-Ottawa scale (NOS). As shown in Figure 2, assessment of risk of bias indicated that all RCTs has low levels of potential bias. Comparatively, all of the retrospective studies adopted an appropriate protocol for treatment assignment and had high scores $(\geq 7)$ assess by NOS (Table S2). Matching criteria between the groups were variable. All of the included studies mentioned the length of follow-up and most of them measured the outcomes at different time points during their trials.

\section{Characteristics of included studies}

The characteristics of the included studies were shown in Table 2. Three of the included article were RCTs (evident level 2b) (21-23), one was prospective nonrandomized trial (27) and five were retrospective studies declared prospective data collection $(11,24-26,28)$. All of them had evidence level $3 \mathrm{~b}$. Baseline characteristics of patients in included studies are presented in Table 3. 


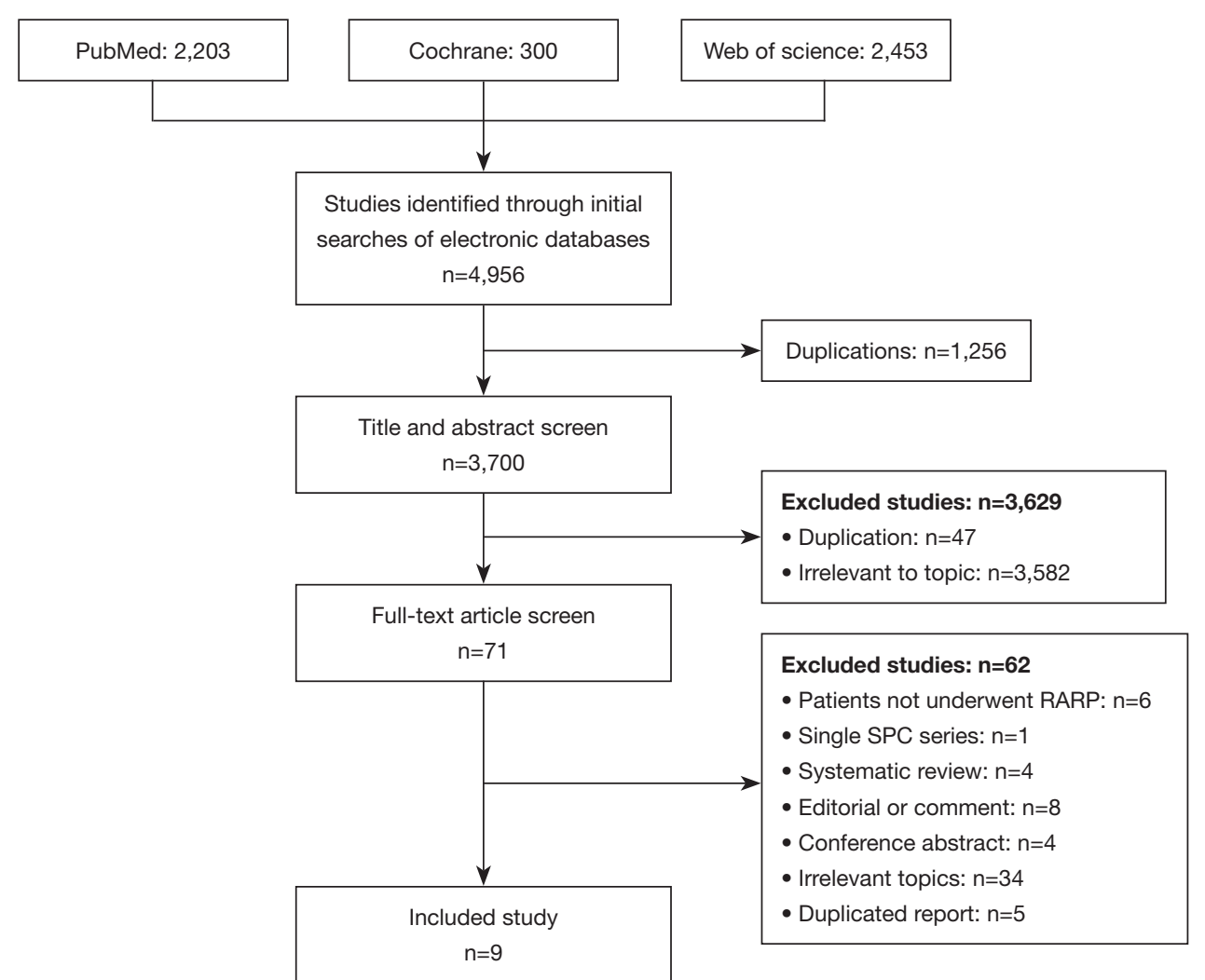

Figure 1 Flow diagram of studies identified included and excluded. SPC, suprapubic catheter; RARP, robot-assisted radical prostatectomy.

\section{Outcomes}

The outcome reported by each study was shown in Table S1. Most studies reported the score of postoperative pain at more time points. The studies that assess the postoperative pain by VAS or other 10-point scale were included in the meta-analysis (Table 4).

\section{Early postoperative pain $(\leq$ POD 3$)$}

Five studies $(21-23,25,27)$ (523 patients) were included in the meta-analysis. Two of them $(25,27)$ found the SPC decreased the early postoperative pain compared to TUC, while three RCTs (21-23) found no significant difference between the groups. A test for heterogeneity in Not RCTs subgroup $\left(\chi^{2}=0.74, \mathrm{P}=0.39, \mathrm{I}^{2}=0 \%\right)$ and RCTs subgroup $\left(\chi^{2}=2.13, P=0.35, I^{2}=6 \%\right)$ was not significant.

Pooling data of these five studies showed a small statistically significant difference in favor of SPC. A test for heterogeneity between the five studies was positive $\left(\chi^{2}=20.37, \mathrm{P}=0.0004, \mathrm{I}^{2}=80 \%\right)$, so a random-effect meta- analysis was performed between the groups (MD: -0.70 ; 95\% CI: -1.37 to $-0.02 ; \mathrm{P}=0.04$ ) (Figure 3).

\section{Later postoperative pain ( $\geq$ POD5)}

Differ from early postoperative pain, pooling data of five studies $(22,23,25,27,28)$ that assessed later postoperative pain found a significant difference in favor of SPC while only one trial (21) found no difference between groups. A random-effects meta-analysis was performed due to the significant heterogeneity among these six studies $\chi^{2}=15.04$, $\left.\mathrm{P}=0.01, \mathrm{I}^{2}=67 \%\right)$. It was found that there was a statistically significant difference in favor of SPC (MD: $-0.96 ; 95 \% \mathrm{CI}$ : -1.39 to $-0.52 ; \mathrm{P}<0.00001$ ) (Figure 4 ).

\section{Long term urinary incontinence ( $>1$ pad per day)}

Seven studies (904 patients) $(11,22-25,27,28)$ reported the numbers of patients who suffer from urinary incontinence in different time points (Table S1). All of them showed no 

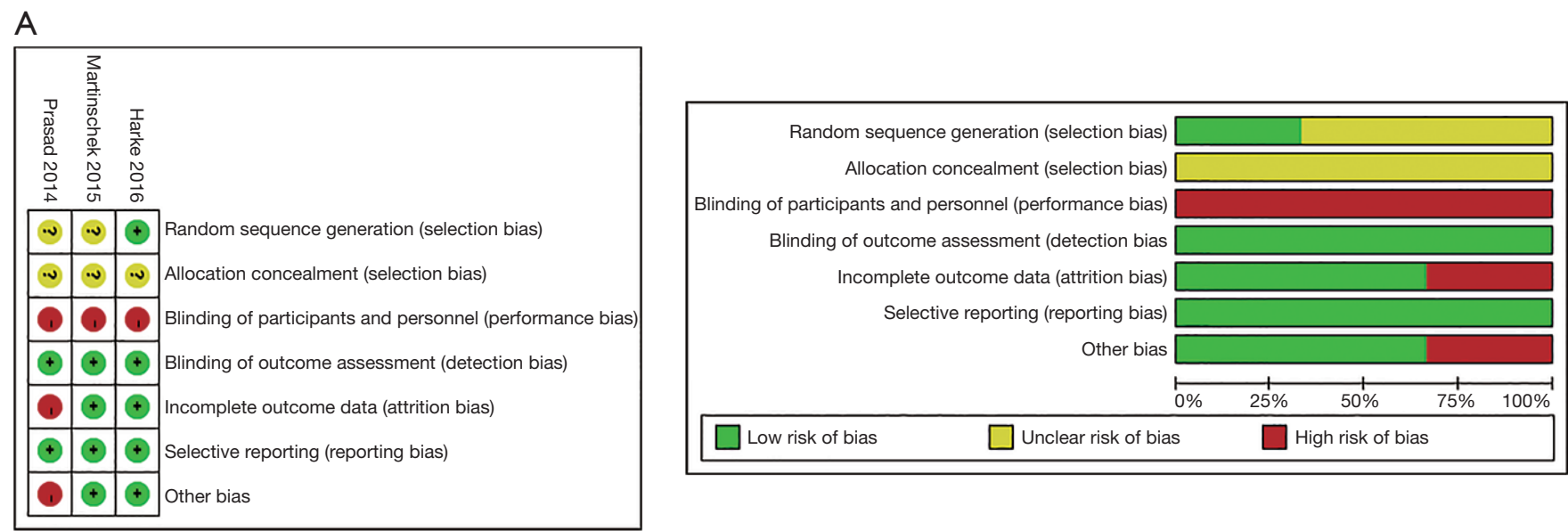

B
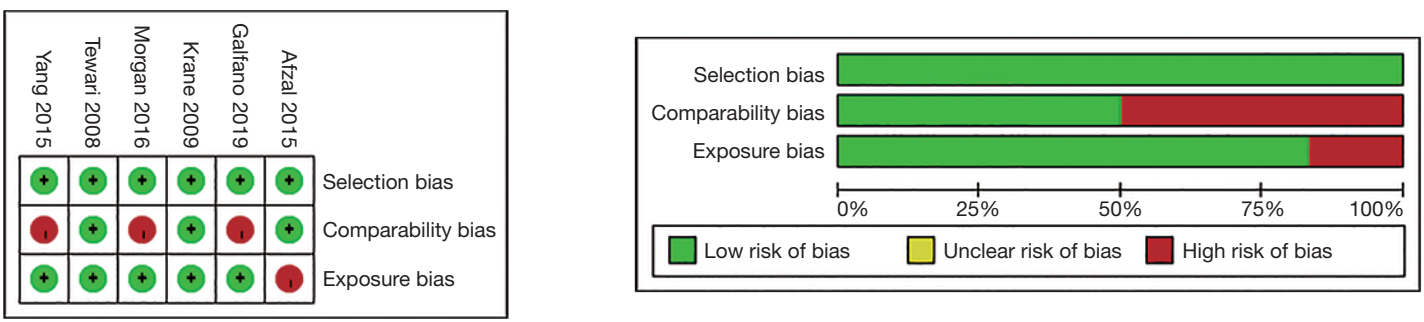

Figure 2 Risk of bias and quality of included studies. (A) The risk of bias graph and summary of three randomized controlled trials (RCTs) that were included. The risk of bias was assessed by the Cochrane risk of bias tool; (B) the methodological quality of five retrospective studies. The quality was assessed by the modified Newcastle-Ottawa scale (NOS).

Table 2 Characteristics of included studies

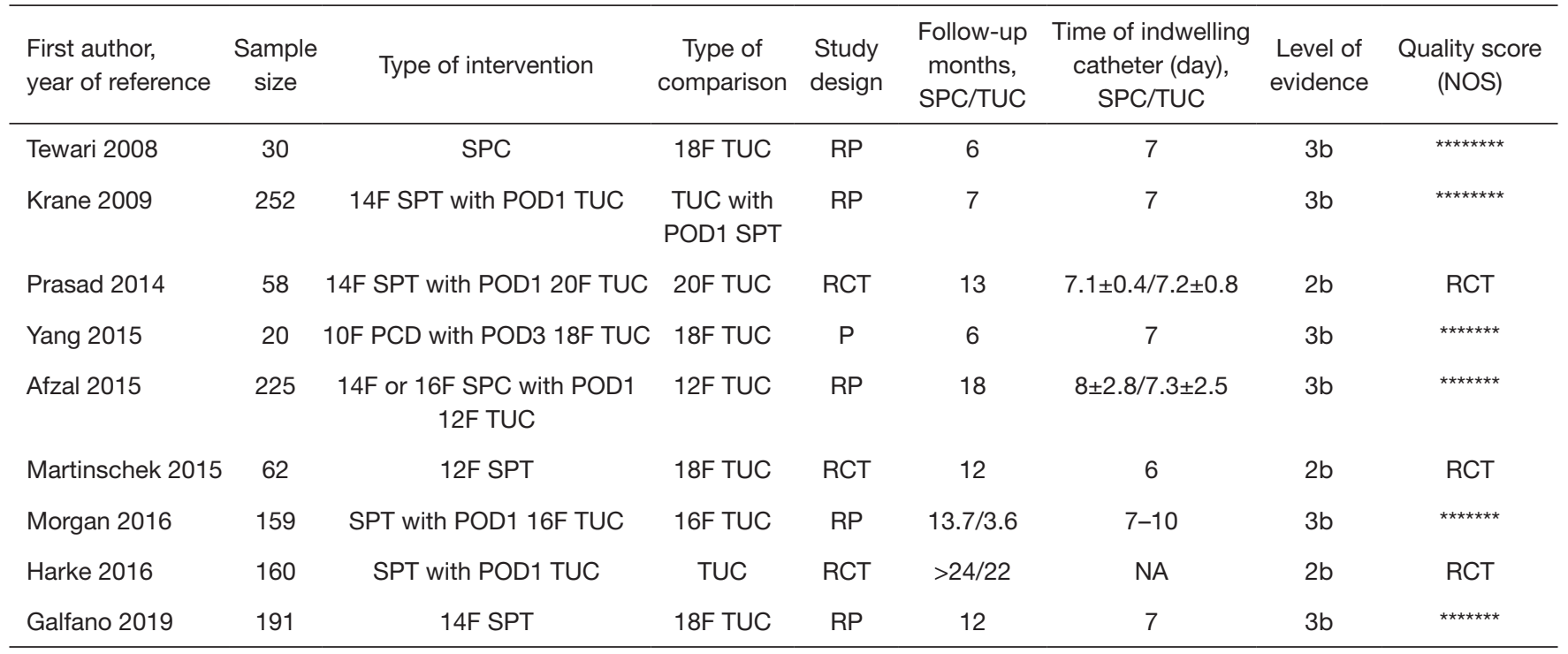

*, the quality score of included studies. SPC, suprapubic catheter; SPT, suprapubic tube; PCD, percutaneous cystostomy device; TUC, transurethral catheter; POD1, until postoperation day 1; RP, retrospective design, prospective data collection; $\mathrm{P}$, prospective design, nonrandomized study; RCT, randomized controlled trial; NA, data not available. 


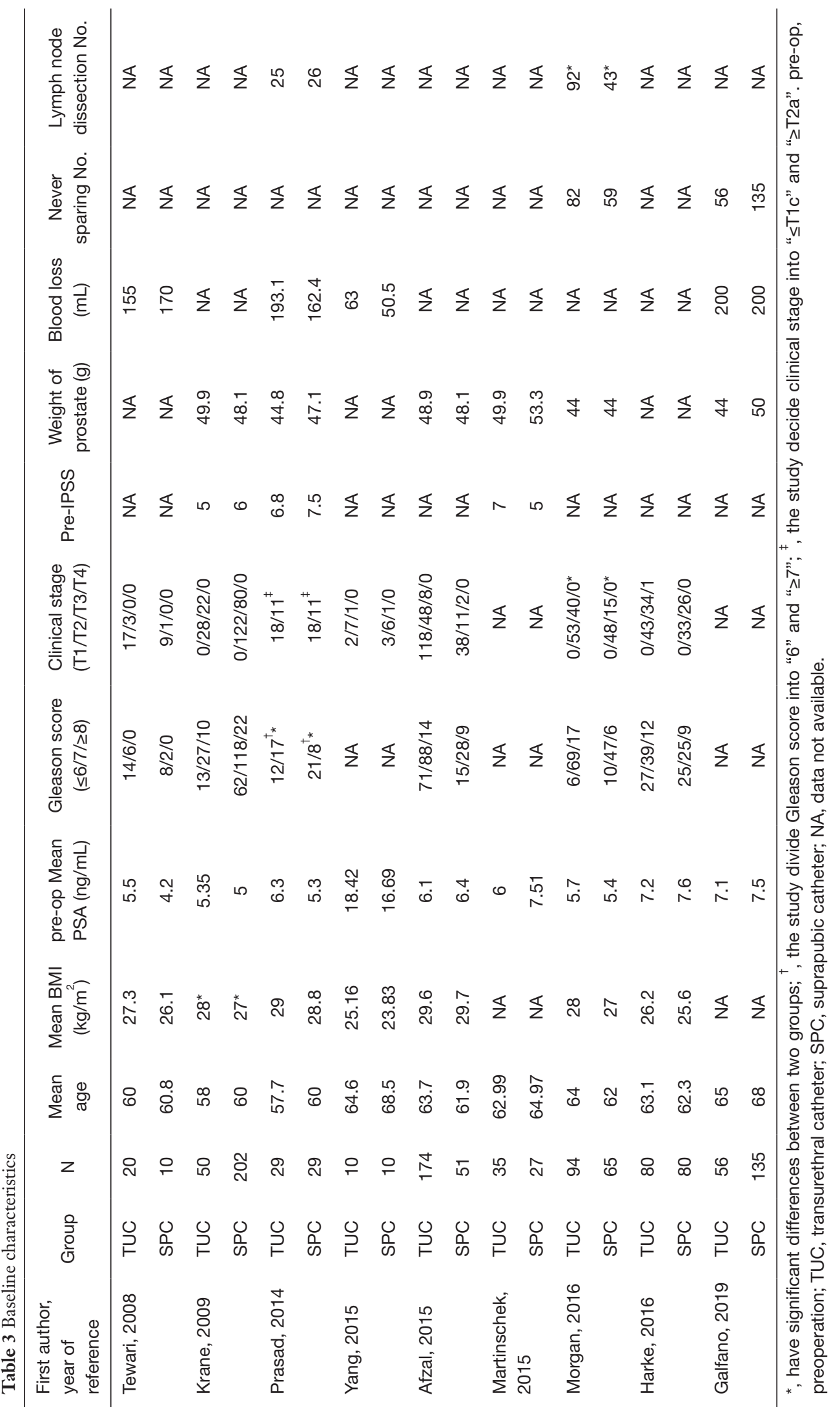


Table 4 primary and secondary outcomes comparing SPC with TUC

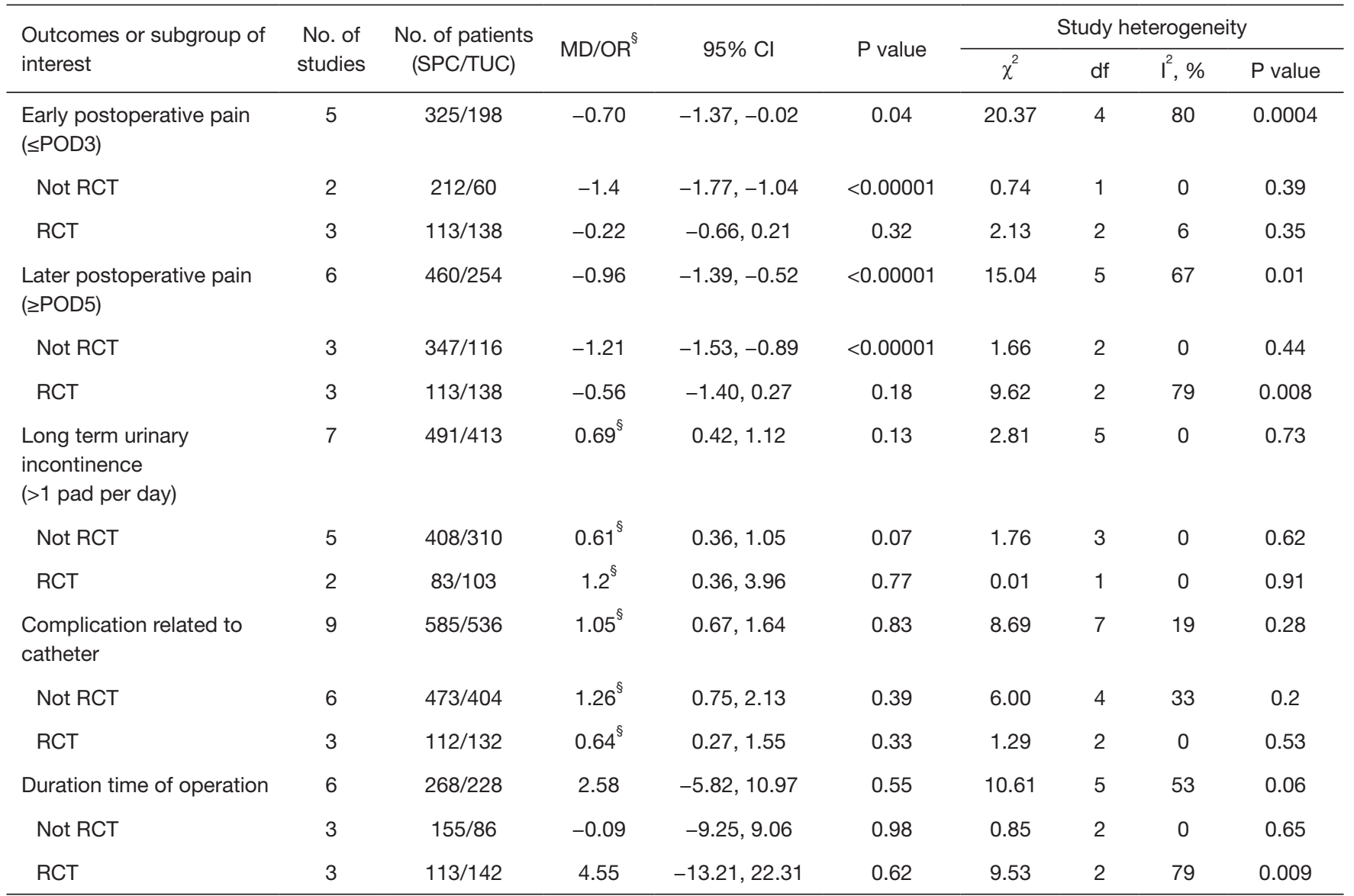

\&, odds ratio. SPC, suprapubic catheter; TUC, transurethral catheter; MD/OR, mean difference/odds ratio; df, degrees of freedom; Cl, confidence interval.

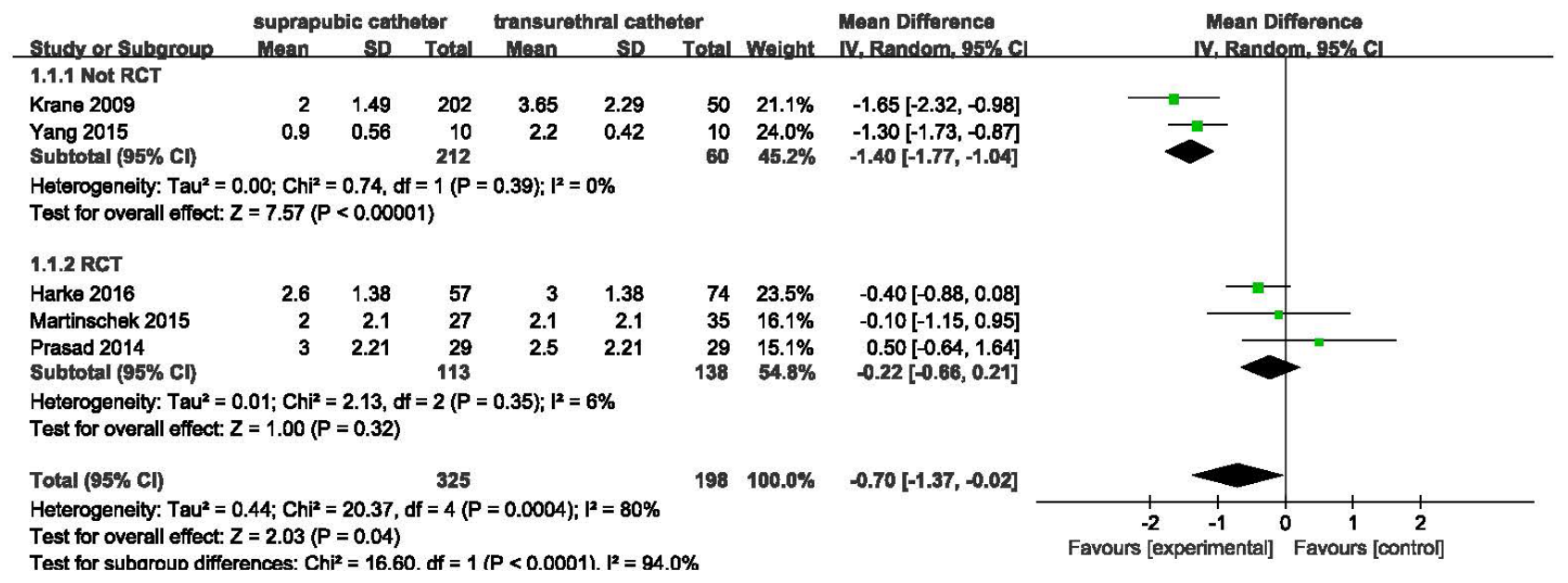

Figure 3 Forest plot and meta-analysis of early postoperative pain $(\leq$ POD3). 


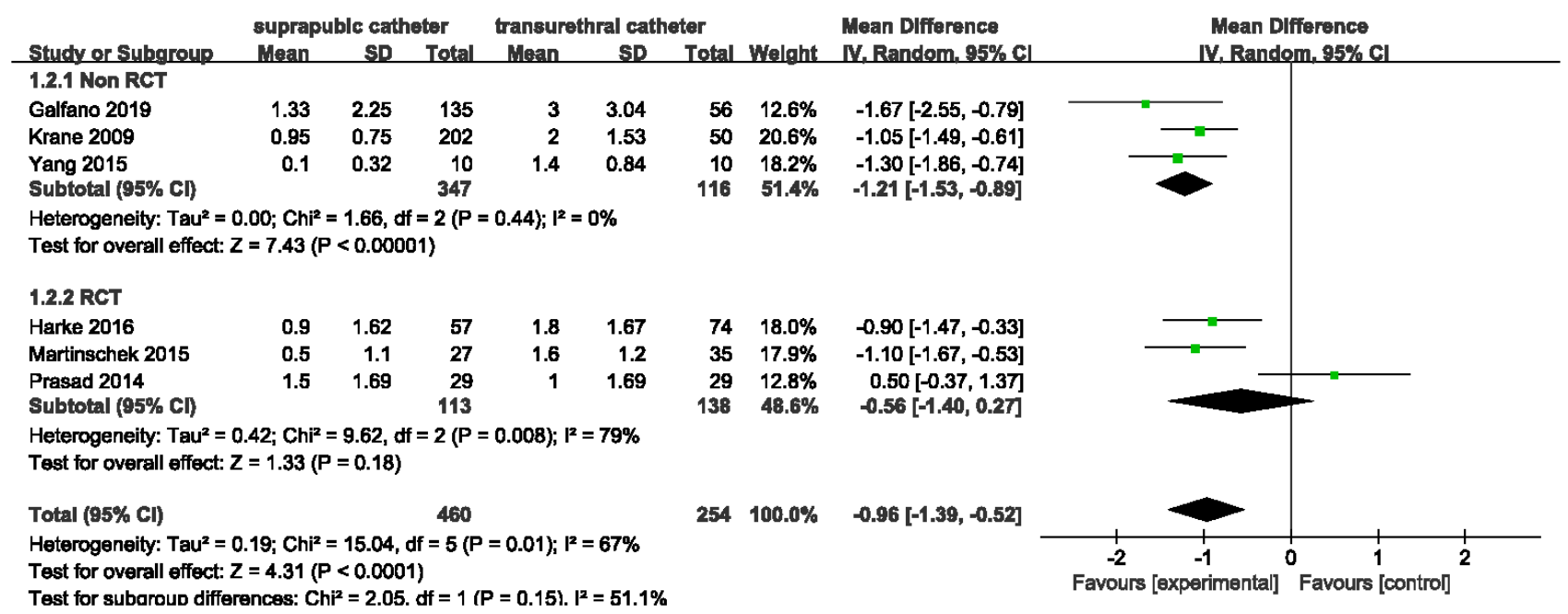

Figure 4 Forest plot and meta-analysis of later postoperative pain ( $\geq$ POD5).

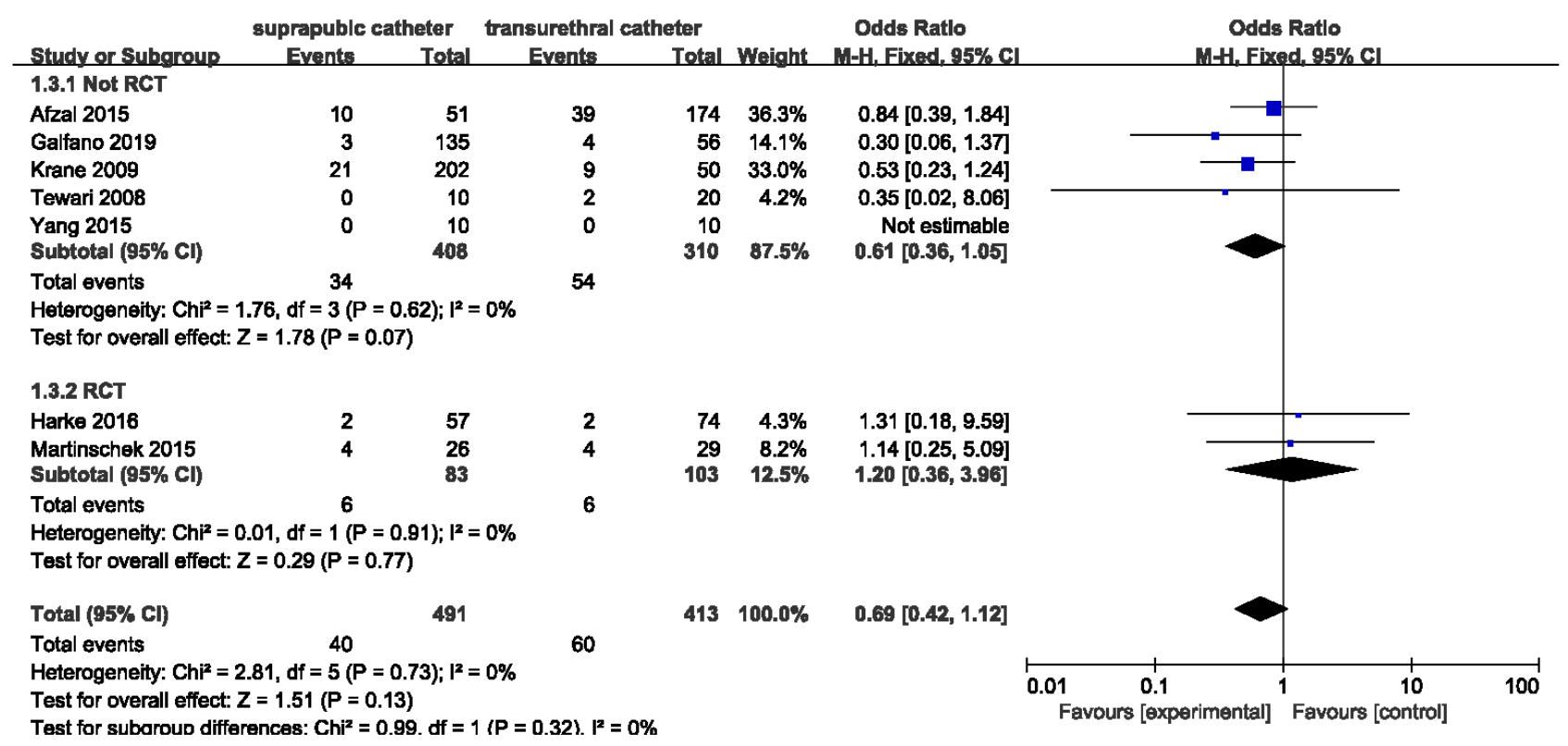

Figure 5 Forest plot and meta-analysis of long-term urinary incontinence rate ( $>1$ pad per day).

significant difference between groups. Figure 5 shows the number of long-term urinary incontinence from which a fix-effect analysis yields an OR of 0.69 (95\% CI: 0.42 to $1.12 ; \mathrm{P}=0.13$ ) for $\mathrm{SPC}$ versus TUC.

\section{Complications related to catheterization}

Pooling data of nine studies $(11,21-28)$ that assessed overall complications related to catheterization in 930 patients showed there is no statistically significant difference of overall complications related to catheterization in the SPC versus TUC groups (OR: 1.05; 95\% CI: 0.67 to 1.64; $\mathrm{P}=0.83)$. The same result occurred in subgroups of RCTs and Not RCTs (Figure 6).

The single type of overall complications related to catheterization hasn't been analyzed since they were 


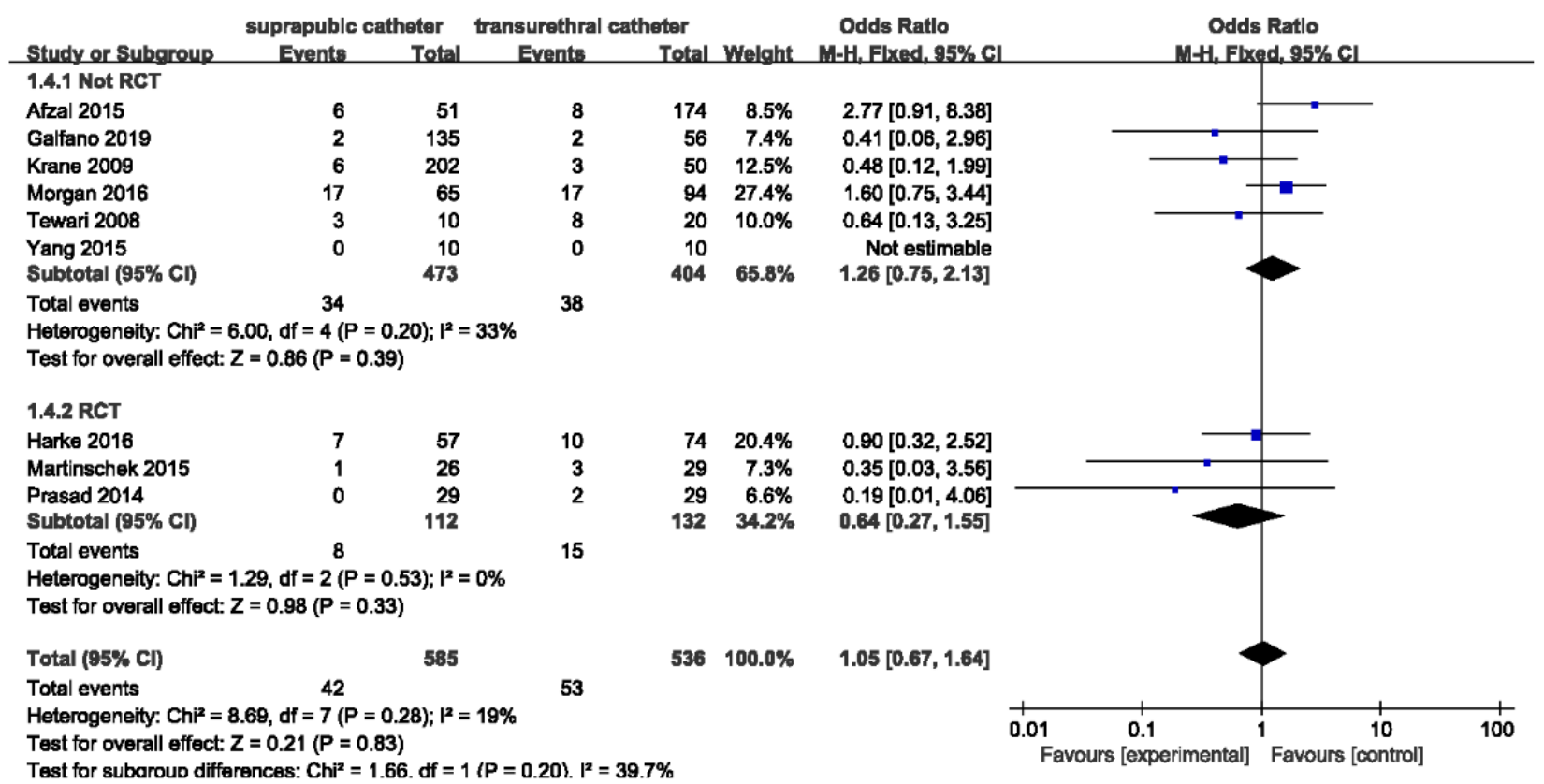

Figure 6 Forest plot and meta-analysis of complications related to catheterization ( $>1$ pad per day).

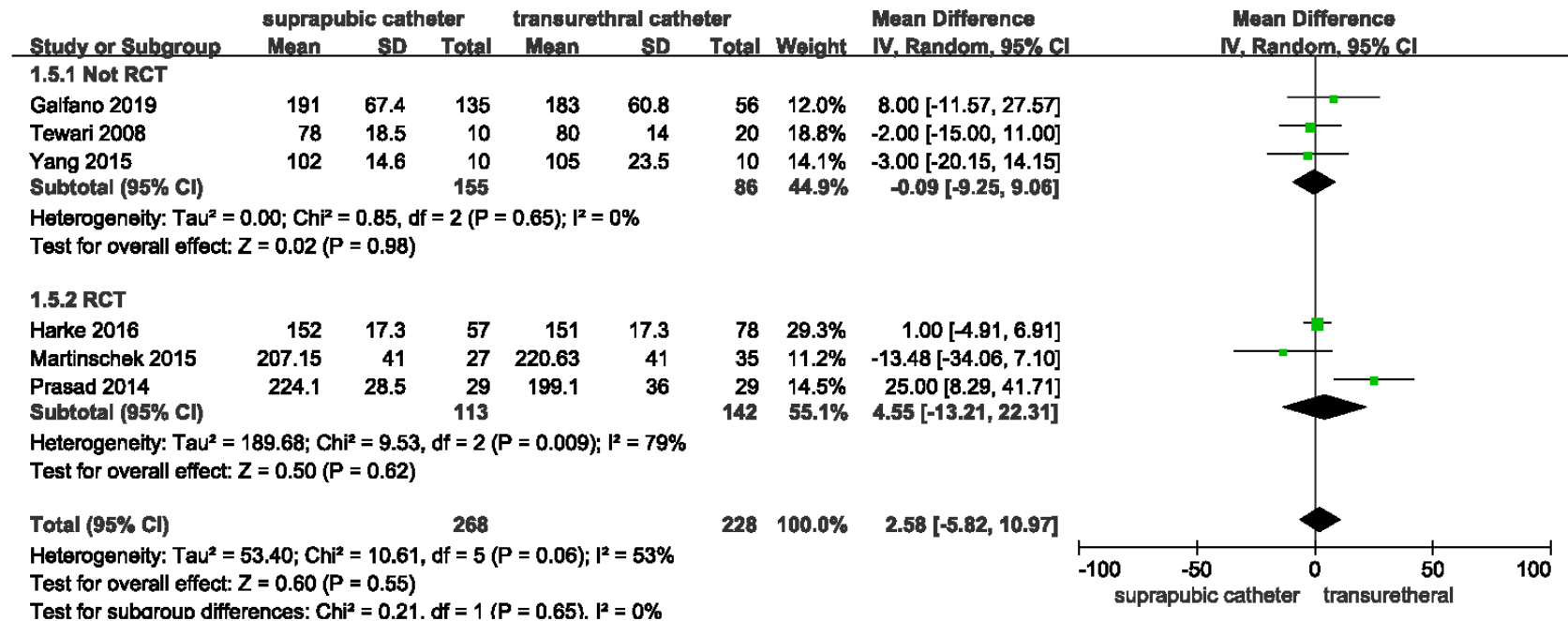

Figure 7 Forest plot and meta-analysis of the duration time of operation.

reported dispersedly in these studies (Table S1).

\section{Duration of operation}

Six studies (496 patients) $(11,21-23,27,28)$ were included in the meta-analysis. A fix-effect meta-analysis was performed between these six studies and no statistically significant difference was found (MD: 2.58; $95 \% \mathrm{CI}:-5.82$ to 10.97 ;
$\mathrm{P}=0.55)$ (Figure 7).

\section{Subgroup analysis}

The results of subgroup analysis were similar to those of total meta-analysis except the primary outcomes. We found no significant difference in postoperative pain either in early time or later period among three RCTs. 
Table 5 Sensitivity analysis of three RCTs and one prospective nonrandomized study

\begin{tabular}{|c|c|c|c|c|c|c|c|c|c|}
\hline \multirow{2}{*}{ Outcomes or subgroup of interest } & \multirow{2}{*}{$\begin{array}{l}\text { No. of } \\
\text { studies }\end{array}$} & \multirow{2}{*}{$\begin{array}{l}\text { No. of patients } \\
\text { (SPC/TUC) }\end{array}$} & \multirow{2}{*}{$\mathrm{MD} / \mathrm{OR}^{\S}$} & \multirow{2}{*}{$95 \% \mathrm{Cl}$} & \multirow{2}{*}{$P$ value } & \multicolumn{4}{|c|}{ study heterogeneity } \\
\hline & & & & & & $\chi^{2}$ & df & $I^{2}, \%$ & $P$ value \\
\hline Early postoperative pain ( $\leq$ POD3) & 4 & $123 / 148$ & -0.44 & $-1.19,0.30$ & 0.24 & 14.33 & 3 & 79 & 0.002 \\
\hline Later postoperative pain ( $\geq$ POD5) & 4 & $123 / 148$ & -0.77 & $-1.41,-0.13$ & 0.02 & 12.40 & 3 & 76 & 0.006 \\
\hline $\begin{array}{l}\text { Long term urinary incontinence } \\
\text { (>1 pad per day) }\end{array}$ & 3 & $93 / 113$ & $1.20^{\S}$ & $0.36,3.96$ & 0.77 & 0.01 & 1 & 0 & 0.91 \\
\hline Duration time of operation & 4 & $123 / 152$ & 2.85 & $-10.05,15.76$ & 0.66 & 9.89 & 3 & 70 & 0.02 \\
\hline
\end{tabular}

SPC, suprapubic catheter; TUC, transurethral catheter; MD/OR, mean difference/odds ratio; df, degrees of freedom; Cl, confidence

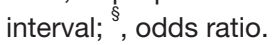

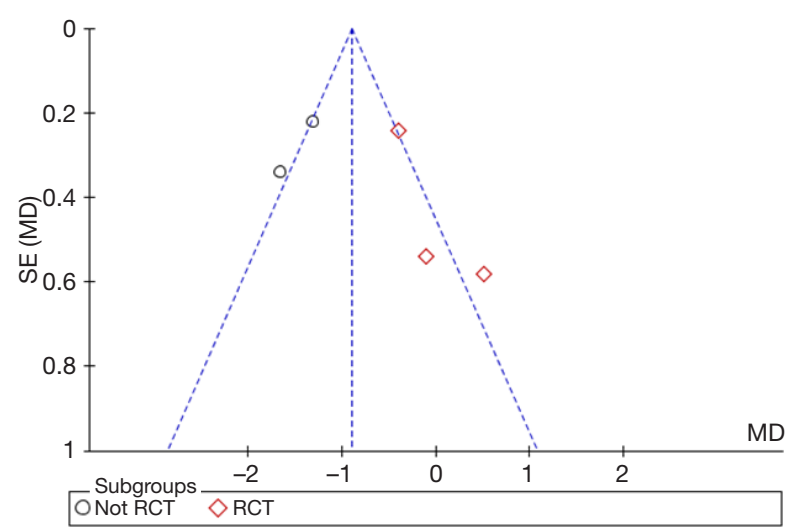

Figure 8 Funnel plots illustrating meta-analysis of early postoperative pain $(\leq$ POD3). SE, standard error; MD, mean difference.

\section{Sensitivity analysis and publication bias}

Three RCTs (21-23) and one prospective nonrandomized studies (27) were included in the sensitivity analysis (Table 5). The degree of between-study heterogeneity decreased slightly for early postoperative pain but increased slightly for later postoperative pain and duration of the operation. There was no change in the significance of any of the outcomes except for early postoperative pain, which was shown no significant difference between SPC and TUC group (MD: $-0.44 ; 95 \% \mathrm{CI}:-1.19$ to $0.30 ; \mathrm{P}=0.24$ ).

In comparison with TUC, a single statistical outlier was identified in the meta-analysis of operative time. Morgan et al have shown that the median operative time for TUC group was significantly shorter than the SPC group (177 vs. 230 minutes, $\mathrm{P}<0.0001)$. However, the authors of the trial considered the reason was not related to SPC placement alone, which took only 5 to 10 minutes (26). So, we remove the data to reduce the evidence of publication bias.

A funnel plot of the studies included in this metaanalysis that reported early postoperative pain was shown in Figure 8 . All studies nearly lie inside the $95 \%$ CIs, with an even distribution around the vertical, indicating no obvious publication bias.

\section{Discussion}

This meta-analysis of three RCTs, one prospective nonrandomized trial and five retrospective studies including 1,121 patients comparing the efficacy of SPC and TUC showed that SPC would decrease the postoperative pain either in early time or the later period while without showing an increase in the rate of complications related to catheterization. This meta-analysis found no significant differences in long-term incontinence rate and duration time of operation.

The primary outcome was postoperative pain. Many authors have indicated that TUC can be removed within 3-5 days of prostatectomy (23). On one hand, Martinschek et al. (22) demonstrated less catheter-associated pain could be found in the SPT group in the later period, on the other hand, Harke et al. found catheter-associated pain had no significant difference between TUC and SPC group after POD 5 and drew a potential conclusion that the major benefit of supra-pubic catheter can be seen when the patient is fully mobilized (23). Therefore, we grouped the primary outcome into the early time and the later period.

In the most recently systematic review written by Jian et al. (29), they included only three studies and found that the postoperative pain had no statistic difference between 
the TUC and SPC group by dividing the patients into two groups (with pain and without pain) according to VAS score of overall pain, which was not applicable to other studies (21-23,27). Another systematic review written by Li et al. (30), they indicated that the overall pain after radical prostatectomy has no significant difference between the SPT and UC groups. However, it included pains not related to catheterization. In our study, we used original and quantitative data presented by original trials and found that the SPC was more adopted by patients undergoing RARP than TUC which may limit daily activities both in early time and later period that was similar to other reviews $(7,10)$. Furthermore, we included the data of the most recent study written by Galfano et al. (28) and compared the duration time of operation between SPC and TUC group, and found that there's no significant difference between SPC and TUC group which indicated that SPC would be a potential way for urinary drainage after RARP.

Interestingly, we pooling data of five studies which have shown SPC can decrease the early postoperative pain, but we found no significant difference in the subgroup of RCTs. Pain has both physical and psychological components. In the nonrandomized trials, patients who selected SPC subjectively might have tended to report lower scores. Differ to the result of early postoperative pain, all studies included in meta-analysis showed SPC was associated with lower pain compared to TUC in the later period after RARP except one (21). This finding may represent that the major benefit of SPC can only be seen on the later postoperative day after they fully adapt to it (23), although Prasad et al. considered the most severe pain from the catheter is due to bladder spams which would ease by the first day after operation (21).

The pooling data of long-term incontinence rate and overall postoperative complications suggested that SPC had no significant difference in these two parts compared to TUC while other reviews showed SPC could decrease complication relative to catheterization especially urinary tract infection in other operations $(7,10)$. This finding may result from the particularity of using a catheter after RARP. The catheter is not only used as bladder drainage but also an important component of the healing process of the vesicourethral anastomosis and prevention of anastomotic stricture developed (21). Single type of complication was reported dispersedly in these studies. The further trials should record the number of patients who suffer from these complications respectively. The result of the duration of operation demonstrated that SPC group have no longer operative time compared to TUC group due to the fact that SPC placement only took 5 to 10 minutes $(24,26)$.

The present meta-analysis has the following limitations that must be taken into account. The main limitation is that the limited number of RCTs prevented us from reaching any definitive conclusions. Inadequate random sequence generation and blinding tended to increase the risk of bias although there's no way to enforce blind to the patients. A future original trial should evaluate different complications separately and roundly.

Nevertheless, we applied multiple strategies to identify studies, strict criteria to include and evaluate the methodological quality of the studies, and subgroup and sensitivity analysis to minimize the heterogeneity.

\section{Conclusions}

The present systematic review and meta-analysis reveals SPC is an alternative way for bladder drainage after RARP and it can decrease the postoperative pain while the complications related to catheterization are similar to TUC. Future large-volume, well-designed RCTs are required.

\section{Acknowledgments}

The authors are grateful to Olga, a graduate student at Guangdong University of Foreign Studies, for her help in modifying the grammar in this article.

Funding: This work was supported by the National Natural Science Foundation of China (No. 81472382, No. 81672550); the Guangdong Province Natural Science Foundation (No. 2014A030313079).the Fundamental Research Funds for the Central Universities (No. 14ykpy19); Guangdong Province Science and Technology for Social Development Project (No. 2013B021800107; 2017A020215018); Guangzhou City in 2015 scientific research projects (201510010298); International Science and technology cooperation project of Guangdong province science and technology plan (No. 2016A050502020) to Hai Huang. And also supported by the National Natural Science Foundation of China (No. 81702527), Natural Science Foundation of Guangdong (No. 2015A030310091, No. 2016A030313185), the Medical Scientific Research Foundation of Guangdong (No. A2015027) to Kaiwen Li. And supported by China Scholarship Council to Kaiwen Li and Hai Huang. 


\section{Footnote}

Conflicts of Interest: The authors have no conflicts of interest to declare.

Ethical Statement: The authors are accountable for all aspects of the work in ensuring that questions related to the accuracy or integrity of any part of the work are appropriately investigated and resolved.

\section{References}

1. Torre LA, Bray F, Siegel RL, et al. Global cancer statistics, 2012. CA Cancer J Clin 2015;65:87-108.

2. Mottet N, Bellmunt J, Bolla M, et al. EAU-ESTROSIOG Guidelines on Prostate Cancer. Part 1: Screening, Diagnosis, and Local Treatment with Curative Intent. Eur Urol 2017;71:618-29.

3. Lim SK, Kim KH, Shin TY, et al. Current status of robotassisted laparoscopic radical prostatectomy: how does it compare with other surgical approaches? Int J Urol 2013;20:271-84.

4. Trinh QD, Sammon J, Sun M, et al. Perioperative outcomes of robot-assisted radical prostatectomy compared with open radical prostatectomy: results from the nationwide inpatient sample. Eur Urol 2012;61:679-85.

5. Albani JM, Zippe CD. Urethral catheter removal 3 days after radical retropubic prostatectomy is feasible and desirable. Prostate Cancer Prostatic Dis 2002;5:291-5.

6. Niël-Weise BS, van den Broek PJ. Urinary catheter policies for short-term bladder drainage in adults. Cochrane Database Syst Rev 2005;(3):CD004203.

7. McPhail MJ, Abu-Hilal M, Johnson CD. A meta-analysis comparing suprapubic and transurethral catheterization for bladder drainage after abdominal surgery. Br J Surg 2006;93:1038-44.

8. Hunter KF, Bharmal A, Moore KN. Long-term bladder drainage: Suprapubic catheter versus other methods: a scoping review. Neurourol Urodyn 2013;32:944-51.

9. Bonkat G, Widmer AF, Rieken M, et al. Microbial biofilm formation and catheter-associated bacteriuria in patients with suprapubic catheterisation. World J Urol 2013;31:565-71.

10. Kidd EA, Stewart F, Kassis NC, et al. Urethral (indwelling or intermittent) or suprapubic routes for short-term catheterisation in hospitalised adults. Cochrane Database Syst Rev 2015;(12):CD004203.

11. Tewari A, Rao S, Mandhani A. Catheter-less robotic radical prostatectomy using a custom-made synchronous anastomotic splint and vesical urinary diversion device: report of the initial series and perioperative outcomes. BJU Int 2008;102:1000-4.

12. Moher D, Liberati A, Tetzlaff J, et al. Preferred reporting items for systematic reviews and meta-analyses: the PRISMA statement. BMJ 2009;339:b2535.

13. Stroup DF, Berlin JA, Morton SC, et al. Meta-analysis of observational studies in epidemiology_ a proposal for reporting. Meta-analysis Of Observational Studies in Epidemiology (MOOSE) group. JAMA 2000;283:2008-12.

14. Phillips B, Ball C, Sackett D, et al. Levels of evidence and grades of recommendation. Oxford Centre for Evidencebased Medicine. Available online: http://www.cebm.net/ index.aspx?o=1025. Accessed 26 April, 2012.

15. Higgins JP, Green S. Cochrane Handbook for Systematic Reviews of Interventions. New York, NY: Cochrane Collaboration; 2011.

16. Taggart DP, D'Amico R, Altman DG. Effect of arterial revascularisation on survival: a systematic review of studies comparing bilateral and single internal mammary arteries. Lancet 2001;358:870-5.

17. Stang A. Critical evaluation of the Newcastle-Ottawa scale for the assessment of the quality of nonrandomized studies in meta-analyses. Eur J Epidemiol 2010;25:603-5.

18. Luo D, Wan X, Liu J, et al. Optimally estimating the sample mean from the sample size, median, mid-range, and/or mid-quartile range. Stat Methods Med Res 2018;27:1785-805.

19. Hozo SP, Djulbegovic B, Hozo I. Estimating the mean and variance from the median, range, and the size of a sample. BMC Med Res Methodol 2005;5:13.

20. Wan X, Wang W, Liu J, et al. Estimating the sample mean and standard deviation from the sample size median range and or interquartile range. BMC Med Res Methodol 2014;14:135.

21. Prasad SM, Large MC, Patel AR, et al. Early removal of urethral catheter with suprapubic tube drainage versus urethral catheter drainage alone after robot-assisted laparoscopic radical prostatectomy. J Urol 2014;192:89-95.

22. Martinschek A, Pfalzgraf D, Rafail B, et al. Transurethral versus suprapubic catheter at robot-assisted radical prostatectomy: a prospective randomized trial with 1-year follow-up. World J Urol 2016;34:407-11.

23. Harke N, Godes M, Habibzada J, et al. Postoperative patient comfort in suprapubic drainage versus transurethral catheterization following robot-assisted radical prostatectomy: a prospective randomized clinical 
trial. World J Urol 2017;35:389-94.

24. Afzal MZ, Tobert CM, Bulica E, et al. Modification of Technique for Suprapubic Catheter Placement After Robot-assisted Radical Prostatectomy Reduces Catheterassociated Complications. Urology 2015;86:401-6.

25. Krane LS, Bhandari M, Peabody JO, et al. Impact of percutaneous suprapubic tube drainage on patient discomfort after radical prostatectomy. Eur Urol 2009;56:325-30.

26. Morgan MS, Ozayar A, Friedlander JI, et al. An Assessment of Patient Comfort and Morbidity After Robot-Assisted Radical Prostatectomy with Suprapubic Tube Versus Urethral Catheter Drainage. J Endourol 2016;30:300-5.

27. Yang CJ, Ou YC, Yang CK. Percutaneous cystostomy drainage for early removing urethral catheter in robotic- assisted laparoscopic radical prostatectomy: Improving on patients' discomfort. Urological Science 2015;26:240-2.

28. Galfano A, Secco S, Panarello D, et al. Pain and discomfort after Retzius-sparing robot-assisted radical prostatectomy: a comparative study between suprapubic cystostomy and urethral catheter as urinary drainage. Minerva Urol Nefrol 2019;71:381-5.

29. Jian Z, Feng S, Chen Y, et al. Suprapubic tube versus urethral catheter drainage after robot-assisted radical prostatectomy: a systematic review and meta-analysis. BMC Urol 2018;18:1.

30. Li MX, Cheng P, Yao L, et al. Suprapubic tube compared with urethral catheter drainage after robot-assisted radical prostatectomy: A systematic review and meta-analysis. Asian J Surg 2019;42:71-80.
Cite this article as: $\mathrm{Li} \mathrm{Z,} \mathrm{Li} \mathrm{K,} \mathrm{Wu} \mathrm{W,} \mathrm{Wang} \mathrm{Q,} \mathrm{Ma} \mathrm{X,}$ Lin C, Peng S, Lai Y, Wang F, Huang H. The comparison of transurethral versus suprapubic catheter after robotassisted radical prostatectomy: a systematic review and metaanalysis. Transl Androl Urol 2019;8(5):476-488. doi: 10.21037/ tau.2019.08.25 
Appendix 1 Detail of search strategy

PubMed: (““catheters”[MeSH Terms] OR “catheterization”[MeSH Terms]) OR catheter[Title/

Abstract]) AND (“prostatectomy”[MeSH Terms] OR prostatectomy[Title/Abstract])

Cochrane: prostatectomy and catheter(TI/Ab/KEY)

Web of Science: TS=(prostatectomy and catheter)

Table S1 Detail of outcomes

\begin{tabular}{|c|c|c|c|c|c|c|c|c|c|c|c|c|}
\hline \multirow{2}{*}{$\begin{array}{l}\text { First author, } \\
\text { year of } \\
\text { reference }\end{array}$} & \multirow[b]{2}{*}{ Early postoperative pain ( $\leq$ POD3) } & \multirow[b]{2}{*}{ Later postoperative pain ( $\geq$ POD5) } & \multirow{2}{*}{$\begin{array}{l}\text { No. urinary } \\
\text { incontinence } \\
\text { (>1 pad per day) }\end{array}$} & \multirow{2}{*}{$\begin{array}{l}\text { Duration time } \\
\text { of operation, } \\
\text { mean (min) }\end{array}$} & \multicolumn{8}{|c|}{ No. of complications related to catheter } \\
\hline & & & & & $\begin{array}{l}\text { Postoperative } \\
\text { retention }\end{array}$ & $\begin{array}{l}\text { Catheter } \\
\text { malfunction }\end{array}$ & $\begin{array}{l}\text { Bladder } \\
\text { spasm }\end{array}$ & $\begin{array}{l}\text { Bladder neck } \\
\text { contracture }\end{array}$ & Hematuria & $\begin{array}{l}\text { Skin } \\
\text { irritation }\end{array}$ & Bacteriuria & Overall \\
\hline Tewari 2008 & \multicolumn{2}{|c|}{ Number of patients suffered penile pain (18 vs. 2) } & $\begin{array}{l}2 \text { vs. } 0 \text { at } 12 \text { weeks } \\
\text { postoperation }\end{array}$ & 78 vs. 80 & NR & NR & 8 vs. 3 & 0 vs. 0 & NR & NR & NR & 8 vs. 3 \\
\hline Krane 2009 & $\begin{array}{l}\text { Median } 4 \text { vs. } 2 \text { measured overall pain } \\
\text { by FPS-R at POD2 }\end{array}$ & $\begin{array}{l}\text { Median } 2 \text { vs. } 0 \text { measured overall pain } \\
\text { by FPS-R at POD6 }\end{array}$ & $\begin{array}{l}9 v \mathrm{vs} .21 \text { at } 2 \text { months } \\
\text { postoperation }\end{array}$ & 171 vs. 165 & 3 vs. 5 & NR & 0 vs. 1 & NR & NR & NR & NR & 3 vs. 6 \\
\hline Prasad 2014 & $\begin{array}{l}\text { Mean } 2.5 \text { vs. } 3.0 \text { measured overall pain } \\
\text { by VAS at POD1 }\end{array}$ & $\begin{array}{l}\text { Mean } 1.0 \text { vs. } 1.5 \text { measured overall } \\
\text { pain by VAS at POD7 }\end{array}$ & NR & $\begin{array}{l}199.1 \text { vs. } \\
224.1\end{array}$ & NR & 0 vs. 2 & NR & 0 vs. 0 & NR & NR & NR & 0 vs. 2 \\
\hline Yang 2015 & $\begin{array}{l}\text { Mean } 2.2 \text { vs. } 0.9 \text { measured penile pain } \\
\text { by VAS at POD3 }\end{array}$ & $\begin{array}{l}\text { Mean } 1.4 \text { vs. } 0.1 \text { measured penile } \\
\text { pain by VAS at POD7 }\end{array}$ & $\begin{array}{l}0 \text { vs. } 0 \text { at } 1 \text { month } \\
\text { postoperation }\end{array}$ & 105 vs. 102 & 0 vs. 0 & NR & NR & 0 vs. 0 & NR & NR & NR & 0 vs. 0 \\
\hline Afzal 2015 & \multicolumn{2}{|c|}{ Retrospective measured catheter bothered by a 10 -points scaled at 28 weeks } & $\begin{array}{l}39 \mathrm{vs} .10 \text { at } 6 \text { weeks } \\
\text { postoperation }\end{array}$ & NR & NR & NR & NR & NR & NR & NR & NR & 8 vs. 6 \\
\hline $\begin{array}{l}\text { Martinschek } \\
2015\end{array}$ & $\begin{array}{l}\text { Mean } 2.1 \text { vs. } 2 \text { measured pain caused } \\
\text { by catheter by VAS at POD } 1\end{array}$ & $\begin{array}{l}\text { Mean } 1.6 \text { vs. } 0.5 \text { measured pain } \\
\text { caused by catheter by VAS at POD6 }\end{array}$ & $\begin{array}{l}4 \text { vs. } 4 \text { at } 1 \text { year } \\
\text { postoperation }\end{array}$ & $\begin{array}{l}220.63 \text { vs. } \\
207.15\end{array}$ & 1 vs. 1 & NR & NR & 2 vs. 0 & NR & NR & NR & 3 vs. 1 \\
\hline Morgan 2016 & Number of patients suffered penile pain & & NR & 177 vs. 230 & 0 vs. 3 & 13 vs. 10 & 2 vs. 2 & NR & 1 vs. 1 & 1 vs. 1 & NR & 17 vs. 17 \\
\hline Harke 2016 & $\begin{array}{l}\text { Mean } 3 \text { vs. } 2.6 \text { measured overall pain } \\
\text { by NRS at POD1 }\end{array}$ & $\begin{array}{l}\text { Mean } 1.8 \text { vs. } 0.9 \text { measured overall } \\
\text { pain by NRS at POD5 }\end{array}$ & $\begin{array}{l}2 \text { vs. } 2 \text { at } 2 \text { years } \\
\text { postoperation }\end{array}$ & 151 vs. 152 & 2 vs. 4 & NR & NR & 0 vs. 0 & NR & NR & 8 vs. 3 & 10 vs. 7 \\
\hline Galfano 2019 & $N R$ & $\begin{array}{l}\text { Mean } 3 \text { vs. } 1 \text { measured pain for } \\
\text { urinary drain by vas-nas at POD7 }\end{array}$ & $\begin{array}{l}4 \mathrm{vs} .3 \text { at } 1 \text { year } \\
\text { postoperation }\end{array}$ & 190 vs. 195 & 1 vs. 2 & 1 vs. 0 & NR & NR & NR & NR & NR & 2 vs. 2 \\
\hline
\end{tabular}

POD, postoperation day; FPS-R, faces pain score-revised; VAS, visual analog scale; NRS, numeric rating scale; NR, no record.

Table S2 Risk of bias in retrospective studies using modified (Newcastle-Ottawa scale)

\begin{tabular}{|c|c|c|c|c|c|c|c|c|c|c|}
\hline \multirow[b]{2}{*}{ Study } & \multicolumn{4}{|c|}{ Selection } & \multicolumn{2}{|c|}{ Comparability } & \multicolumn{3}{|c|}{ Exposure } & \multirow[b]{2}{*}{$\begin{array}{l}\text { Quality } \\
\text { score }\end{array}$} \\
\hline & $\begin{array}{l}\text { Representativeness } \\
\text { of the exposed } \\
\text { cohort }\end{array}$ & $\begin{array}{l}\text { Selection of the } \\
\text { non-exposed } \\
\text { cohort }\end{array}$ & $\begin{array}{l}\text { Ascertainment } \\
\text { of exposure }\end{array}$ & $\begin{array}{l}\text { Outcome of } \\
\text { interest was not } \\
\text { present at start }\end{array}$ & $\begin{array}{l}\text { Comparable } \\
\text { for } 1-4^{*}\end{array}$ & $\begin{array}{l}\text { Comparable } \\
\text { for } 5-8^{\star}\end{array}$ & $\begin{array}{l}\text { Assessment } \\
\text { of outcome }\end{array}$ & $\begin{array}{l}\text { Follow-up } \\
\text { long enough }\end{array}$ & $\begin{array}{l}\text { Adequacy of } \\
\text { follow up of } \\
\text { cohorts }\end{array}$ & \\
\hline Tewari 2008 & Yes & Yes & Yes & Yes & $1,2,3,4$ & 5 & Yes & Yes & Yes & 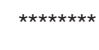 \\
\hline Afzal 2015 & Yes & Yes & Yes & Yes & $1,2,3,4$ & 5,7 & Yes & Yes & No & 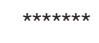 \\
\hline Krane 2009 & Yes & Yes & Yes & Yes & $1,2,3,4$ & $5.6,7$ & Yes & Yes & Yes & $* * * * * * * *$ \\
\hline Morgan 2016 & Yes & Yes & Yes & Yes & $1,2,3$ & 5.7 .8 & Yes & Yes & Yes & 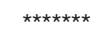 \\
\hline Yang 2015 & Yes & Yes & Yes & Yes & $1,2,4$ & 5 & Yes & Yes & Yes & $\star \star \star \star \star * \star *$ \\
\hline Galfano 2019 & Yes & Yes & Yes & Yes & 1,2 & 7,8 & Yes & Yes & Yes & 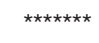 \\
\hline
\end{tabular}

Comparability variables: $1=$ age; $2=$ preoperative PSA; $3=$ Gleason score; $4=$ clinical stage; $5=\mathrm{BMI} ; 6=$ preoperative IPSS; $7=$ weight of prostate; $8=$ nerve sparing. ${ }^{*}$, if all characteristics were comparable, two stars; if preoperative PSA, Gleason score or Clinical stage wasn't comparable, no star; otherwise, one star. 